\title{
DQ impedance stability analysis for the power-controlled grid-connected inverter
}

\author{
Chuanyue Li, Member, IEEE, Jun Liang, Senior Member, IEEE, Liana M. Cipcigan, Member, IEEE, \\ Wenlong Ming, Member, IEEE, Frederic Colas, Xavier Guillaud, Member, IEEE
}

\begin{abstract}
For a grid-connected inverter requiring the ac voltage magnitude and the active power control, both vector control and power synchronization control can be applied. The stability comparison based on the dq impedance stability analysis between both control are carried out via three factors including the grid impedance, the inner current loop and the virtual impedance. The dq impedances of the inverter based on both control are derived. The determinant of the impedance ratio matrix is used for the stability analysis. The bode plot of the grid impedance and the inverter impedance are present to assist the stability analysis and explain their interactions. It is found that increasing the grid impedance and the cut-off frequency of the current loop stabilize the inverter with the power synchronization control, which is converse to the vector control. Furthermore, the inverter with the power synchronization control may suffer the instabilities when connecting to a strong grid. The virtual inductor and resistor are proposed to enhance the stability for the vector control and the power synchronization control respectively. The simulation validation using Matlab/Simulink is performed.
\end{abstract}

Index Terms-Impedance stability analysis, VSC, small-signal stability analysis, small-signal modeling

\section{INTRODUCTION}

$\mathbf{T}$ HREE-phase voltage source converters (VSCs) are widely used as grid-connected inverters to assist the integration of renewable energies. Inverters with the commonused vector control may suffer instabilities with a weak grid [1]. Because the point-of-common-coupling voltage that tracked by phase-locked loop (PLL) is not stiff. The power synchronization control [2], that emulates the operation of synchronization machines, is proposed as an alternative power control of the grid-connected inverter for a stable connection to the weak grid. The inner current loops are normally applied for both power control in order to protect the semiconductor switches from the overcurrent.

The stability analysis are essential for both control to improve the stability and further avoid the instability. Two

Manuscript created August 1, 2019; revised November 17, 2019 and February 24, 2020; accepted April 13, 2020. This work was supported by UK National Grid Electricity Transmission under Grand NIA_NGTO001. (Corresponding author: Jun Liang)

C. Li, J. Liang, L. Cipcigan, W. Ming are with the School of Engineering, Cardiff University, Cardiff, CF24 3AA (email: chuanyue.li@outlook.com; LiangJ1; CipciganLM; MingW\{ @ cardiff.ac.uk\}).

X. Guillaud are with Univ. Lille, Arts et Metiers Institute of Technology, Centrale Lille, HEI, ULR 2697- L2EP - Laboratoire d'Electrotechnique et d'Electronique de Puissance, F-59000 Lille, France (email: xavier.guillaud@centralelille.fr).

F. Colas is with Arts et Metiers Institute of Technology, Univ. Lille, Centrale Lille, HEI, HESAM Universite, EA 2697 - L2EP - Laboratoire d'Electrotechnique et d'Electronique de Puissance, F-59000 Lille, France (email: Frederic.colas@ensam.eu). stability analysis methods, which are the state-space stability analysis [3] and impedance stability analysis [4], can be used based on the small-signal linearization. For the state-space stability analysis, a high order and specified matrix is required in order to find all system poles. The impedance stability analysis can do the same pole analysis simply based on the impedance ratio via pole maps or Nyquist plot. Additionally, the impedance of the inverter can be figured as the bode plot to assist the analysis. The impedance stability analysis is achieved via the impedance ratio [4] that is determined by the admittance of the inverter and the impedance of the grid.

For a dq controlled three-phase inverter, the admittance in the dq domain [5] or in the sequence domain [6] can be applied for the stability analysis. Their frequency analysis are therefore referred to the dq frame and stationary frame respectively. An additional complex space vector derivation [7] [8] is required to derive the sequence admittance. It found that the $\mathrm{dq}$ admittance can be equivalently transferred to a modified sequence admittance [9]. Both admittances are coupled $2 \times 2$ matrices due to the synchronisation of $\mathrm{dq}$ frame control and asymmetrical outer loop. The couplings was ignored [10] [6] for the stability analysis due to its small magnitude. The following studies show that the couplings must be considered for an accurate stability analysis [11] [12].

The impedance ratio is a $2 \times 2$ matrix due to the dq frame control. Generalized Nyquist Criterion [10] is therefore applied for both impedance-ratio matrix's eigenvalues for the stability analysis. It is commonly used in the grid-connected inverter system [13] [5] [14] [15] [16]. However, both eigenvalues have to be analysed, and the coupled matrix brings difficulties to derive the transfer functions of its eigenvalues.

The determinant of the impedance-ratio matrix, which is derived simply, is used for three-phase rectifier's stability analysis [17] [18] in 1990s. Recently it is applied for the inverter system as an alternative impedance stability analysis method [19] [20]. Only the determinant is figured as the pole map or Nyquist plot for the stability analysis, which simplifies the analysis process. Another to the multi-input and multi-output dq impedance can be converted into its sequence domain single-input and single-output equivalents [21]. Then the Nyquist Criterion other than Generalized Nyquist Criterion can be applied.

The grid-connected inverter using the vector control are widely studied via the dq impedance stability analysis. The factors with a negative impact on the stability are unveiled, such as large cut-off frequency of the phase-locked loop (PLL) [13] and current control loop [22], high power injection 


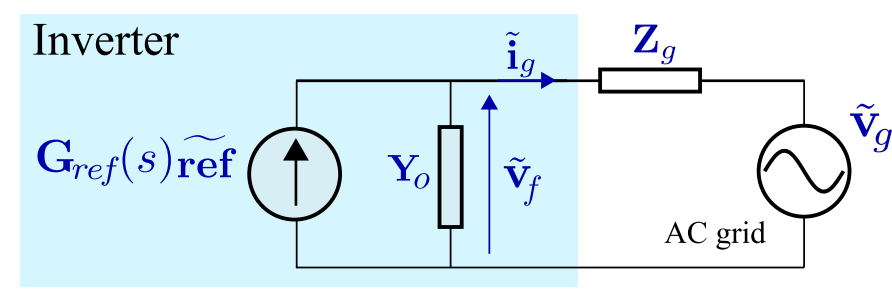

Fig. 1: Impedance model of a grid-connect inverter

from the inverter and large grid impedance [5]. The stability of a multiple inverter system can also be validated via the impedance method [15] [16]. The synchronization stability issues between inverters can be avoided via the design of the PLL [14].

The grid-connected inverter using the power synchronization control for a stable connection to a weak grid [2] is extensively studied via the stability analysis recently years. The stability limitation [23], the robust control design [24], and the transient stability analysis [25] are carried out for the power synchronization control. It is revealed based on the impedance stability analysis that the subsynchronous damping can be benefited from the inverter with power synchronization control [26], and the stability of the power synchronization control can be improved via the high-pass filter [27]. The comparison studies of the power synchronization control based on the impedance method between the current control and the voltage control are carried out in [28].

However, a comprehensive stability comparison study between the conventional vector control and the power synchronization control for regulating the ac voltage magnitude and the active power is not carried out yet. In this paper, the stability influence of the connected grid ranging from a strong grid to a weak grid is studied. The frame synchronization and outer loops of both control are different, except the inner current control as shown in Figs. 3 and 4. Therefore, the stability comparison on the inner current loop is carried out based on the various cut-off frequency. The different type of virtual impedance control for enhancing the stability of both control are also proposed and compared. The dq impedance stability analysis based on the determinant is used in the paper.

\section{DQ IMPEDANCE STABILITY ANALYSIS}

\section{A. $d q$ impedance stability analysis}

Grid-connected inverters normally work as a current source in the d-q frame and its small-signal model is built according to the Norton law, as shown in Fig. 1. ref is the reference deviation of the control system and $\mathbf{G}_{r e f}(s)$ is its gain factor from the control.

From the inverter side, the relation between the voltage behind the filter $\widetilde{\mathbf{v}}_{f}$ and the feeding current $\widetilde{\mathbf{i}}_{g}$ is derived as:

$$
\widetilde{\mathbf{i}}_{g}=\mathbf{G}_{r e f} \widetilde{\mathbf{r e f}}+\mathbf{Y}_{o} \widetilde{\mathbf{v}}_{f}
$$

Where the bold parameter stands for its d-q matrix parameters such as $\widetilde{\mathbf{i}_{g}}=\left[\begin{array}{c}\widetilde{i}_{g d} \\ \widetilde{i}_{g q}\end{array}\right]$.

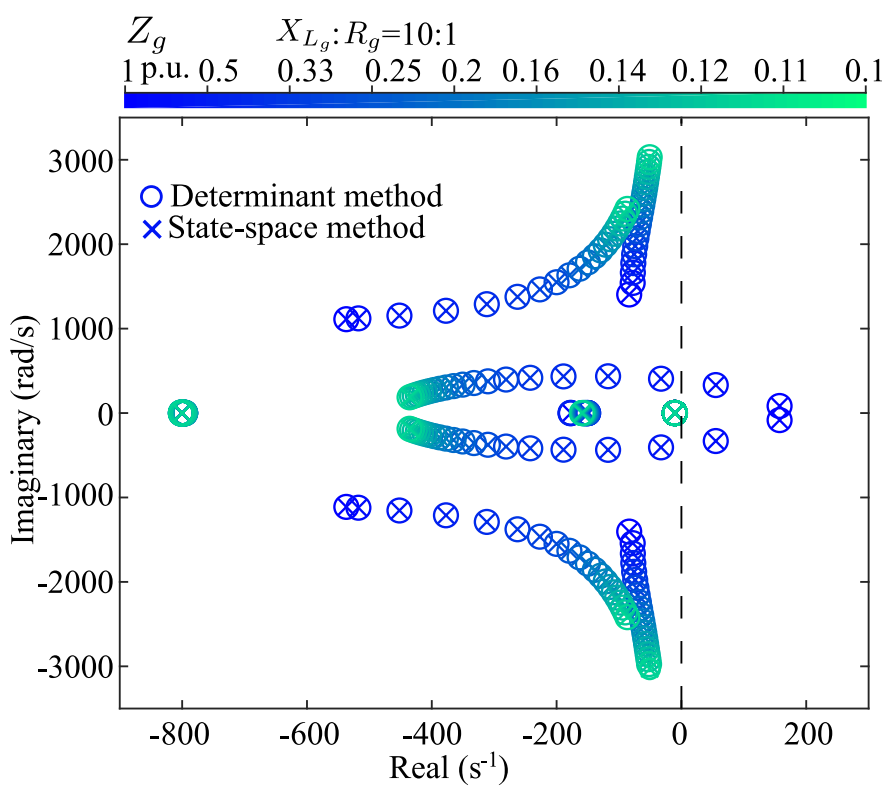

Fig. 2: Comparison between the state-space method and the determinant-based impedance method

From the grid side, the relation between feeding current $\widetilde{\mathbf{i}}_{g}$ and the grid voltage $\widetilde{\mathbf{v}}_{g}$ is derived as:

$$
\widetilde{\mathbf{v}}_{f}-\widetilde{\mathbf{v}}_{g}=\mathbf{Z}_{g} \widetilde{\mathbf{i}}_{g}
$$

Substituting $\widetilde{\mathbf{v}}_{f}$ in (1) with (2) yields:

$$
\widetilde{\mathbf{i}_{g}}=\mathbf{G}_{r e f} \widetilde{\mathbf{r e f}}+\mathbf{Y}_{o} \mathbf{Z}_{g} \widetilde{\mathbf{i}}_{g}+\mathbf{Y}_{o} \widetilde{\mathbf{v}}_{g}
$$

Rearranging (3) for $\widetilde{\mathbf{i}}_{g}$ yields:

$$
\widetilde{\mathbf{i}_{g}}=\left(\mathbf{I}-\mathbf{Z}_{g} \mathbf{Y}_{o}\right)^{-1}\left(\mathbf{G}_{r e f} \widetilde{\mathbf{r e f}}+\mathbf{Y}_{o} \widetilde{\mathbf{v}}_{g}\right)
$$

Where the impedance ratio matrix is $\left(\mathbf{I}-\mathbf{Z}_{g} \mathbf{Y}_{o}\right)^{-1}$.

For the impedance stability analysis [4] [29] [5], the impedance ratio matrix is considered for the system stability analysis due to no right-plane poles from $\mathbf{G}_{r e f} \& \mathbf{Y}_{o}$.

\section{B. Impedance stability analysis via the determinant}

It is found that the determinant derived from the impedance ratio matrix is the key factor that determines the system stability. All elements of the impedance ratio matrix are contained in the determinant including couplings, thus their influence on the stability are all accounted. The Nyquist plot or the pole map as the stability analysis tool can be drawn via the determinant to check the right-plane poles. The mechanism of the determinant as the key factor for the stability analysis is shown below.

The impedance ratio matrix can be reconstructed as two parts: a determinant and an adjacent matrix as shown below:

$$
\left(\mathbf{I}-\mathbf{Z}_{g} \mathbf{Y}_{o}\right)^{-1}=\operatorname{adj}\left(\mathbf{I}-\mathbf{Z}_{g} \mathbf{Y}_{o}\right) \operatorname{det}\left(\left(\mathbf{I}-\mathbf{Z}_{g} \mathbf{Y}_{o}\right)^{-1}\right)
$$

The equivalent admittance $\mathbf{Y}_{O}$ of the inverter has no right-plane poles as mentioned before, neither to the grid impedance $\mathbf{Z}_{g}$. Therefore, no right-plane poles exist in $\operatorname{adj}\left(\mathbf{I}-\mathbf{Y}_{o} \mathbf{Z}_{g}\right)$. It can be concluded via the (5) that the system stability is determined 

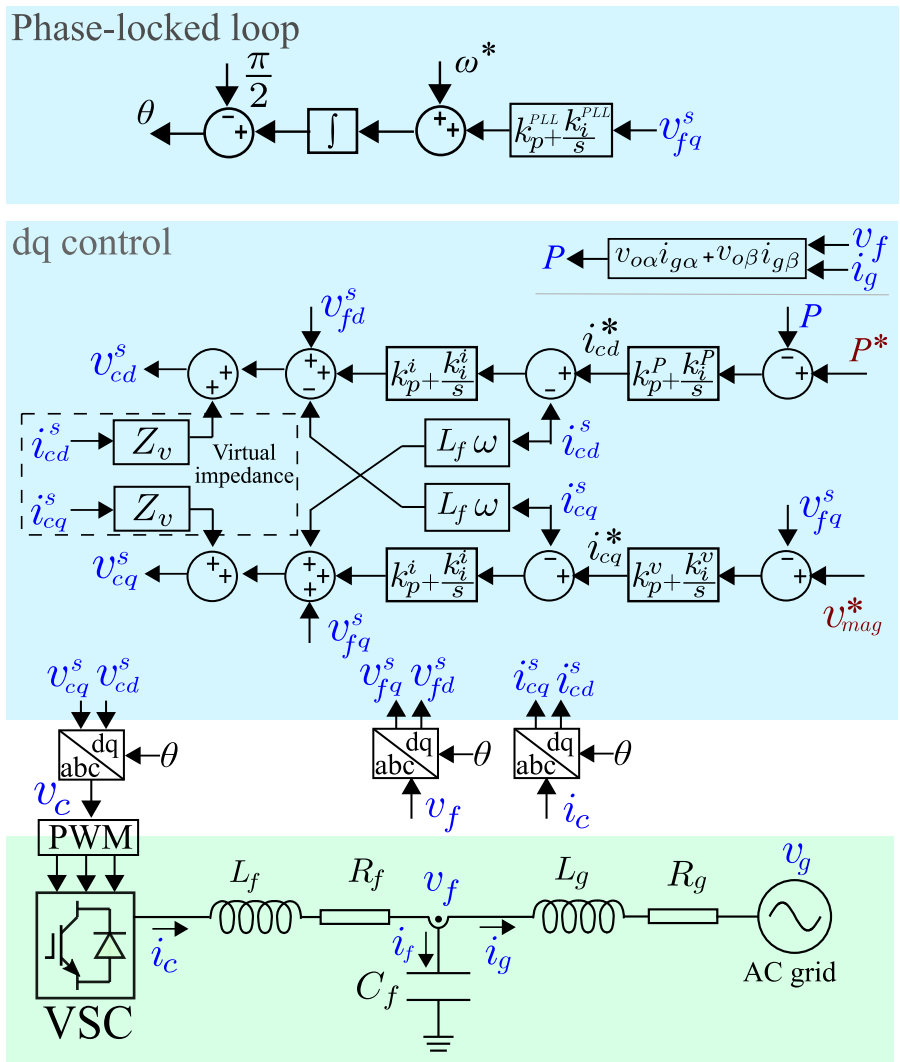

Fig. 3: Vector control

only by $\operatorname{det}\left(\left(\mathbf{I}-\mathbf{Z}_{g} \mathbf{Y}_{o}\right)^{-1}\right)$, which is the determinant of the impedance ratio matrix.

For the stability analysis, one pole map can be used based on the determinant $\operatorname{det}\left(\left(\mathbf{I}-\mathbf{Z}_{g} \mathbf{Y}_{o}\right)^{-1}\right)$ for checking the rightplane poles. The determinant can also be figured as a bode plot for the frequency analysis based on the dq frame.

For validating the determinant-based impedance stability analysis, the state-space method [22] is used for the comparison. The studied system is shown in Fig. 3. The inverter control is simplified as the current control with the PLL. The state-space matrix is derived based on [30]. Pole locus are drawn in Fig. 2 at various grid impedance. As shown in Fig. 2 , the determinant-based method identifies the same poles of the inverter as that of the state-space method.

\section{Impedance analysis via the bode plot}

The determinant method simplifies the dq impedance stability analysis for the grid-connected inverter system. However, $\operatorname{det}\left(\left(\mathbf{I}-\mathbf{Z}_{g} \mathbf{Y}_{o}\right)^{-1}\right)$ involves the matrix multiplication such as $\mathbf{Z}_{g} \mathbf{Y}_{o}$, as shown below:

$$
\mathbf{Y}_{o} \mathbf{Z}_{g}=\left[\begin{array}{cc}
Y_{o}^{d d} Z_{g}^{d d}+Y_{o}^{d q} Z_{g}^{q d} & Y_{o}^{d d} Z_{g}^{d q}+Y_{o}^{d q} Z_{g}^{q q} \\
Y_{o}^{q d} Z_{g}^{d d}+Y_{o}^{q q} Z_{g}^{q d} & Y_{o}^{q d} Z_{g}^{d q}+Y_{o}^{q q} Z_{g}^{q q}
\end{array}\right]
$$

Comparing to (6), (7) is simpler and clearer to explain the interaction, as shown below:

$$
\mathbf{Z}_{o}-\mathbf{Z}_{g}=\left[\begin{array}{cc}
Z_{o}^{d d}-Z_{g}^{d d} & Z_{o}^{d q}-Z_{g}^{d q} \\
Z_{o}^{q d}-Z_{g}^{q d} & Z_{o}^{q q}-Z_{g}^{q q}
\end{array}\right]
$$

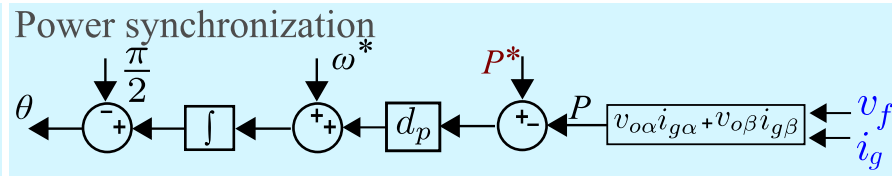

\section{dq control}

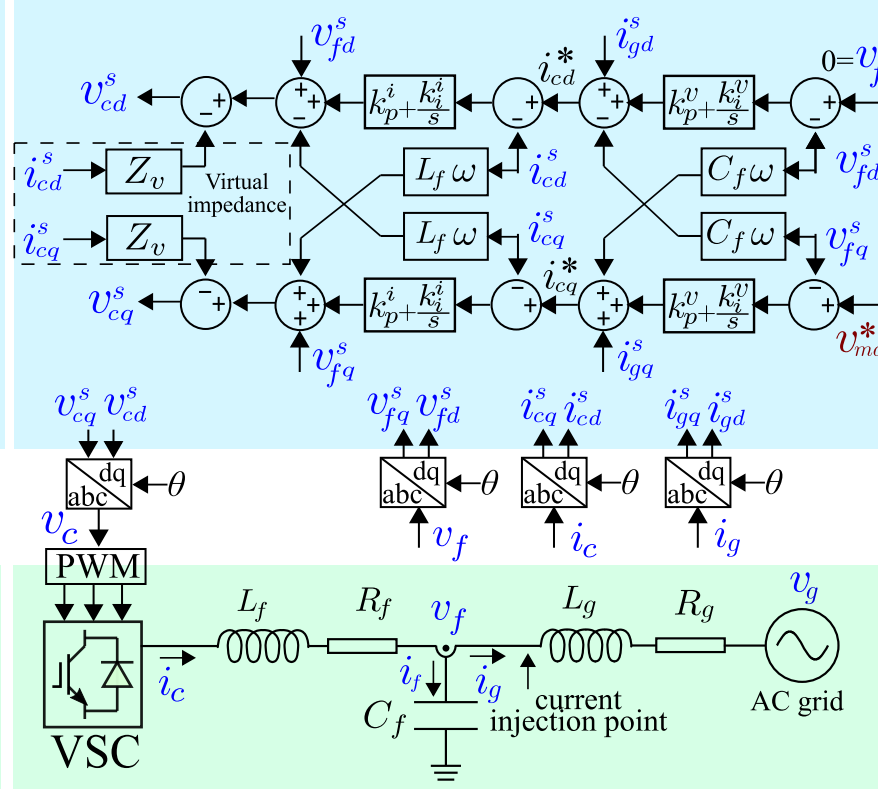

Fig. 4: Power synchronization control

Therefore, the further reconstruction of $\operatorname{det}\left(\left(\mathbf{I}-\mathbf{Z}_{g} \mathbf{Y}_{o}\right)^{-1}\right)$ is required and shown below:

$$
\begin{aligned}
\operatorname{det}\left(\left(\mathbf{I}-\mathbf{Z}_{g} \mathbf{Y}_{o}\right)^{-1}\right) & =\frac{\operatorname{det}\left(\mathbf{Y}_{o}^{-1}\right)}{\operatorname{det}\left(\mathbf{Z}_{o}-\mathbf{Z}_{g}\right)} \\
\operatorname{det}\left(\left(\mathbf{I}-\mathbf{Z}_{g} \mathbf{Y}_{o}\right)^{-1}\right) & =\frac{\operatorname{det}\left(\mathbf{Z}_{g}^{-1}\right)}{\operatorname{det}\left(\mathbf{Y}_{g}-\mathbf{Y}_{o}\right)}
\end{aligned}
$$

where $\mathbf{Z}_{o}$ is the equivalent impedance of the inverter.

With a constant inverter admittance $\mathbf{Y}_{o}$, the stability influence of various $\mathbf{Z}_{g}$ is analysed based on (8) via $\frac{1}{\operatorname{det}\left(\mathbf{Z}_{o}-\mathbf{Z}_{g}\right)}$. All elements of $\left(\mathbf{Z}_{o}-\mathbf{Z}_{g}\right)$ are calculated straightly compared to $\mathbf{Z}_{g} \mathbf{Y}_{o}$. The stability influence of each element of $\left(\mathbf{Z}_{o}-\mathbf{Z}_{g}\right)$ on $\frac{1}{\operatorname{det}\left(\mathbf{Z}_{o}-\mathbf{Z}_{g}\right)}$ can be found via their bode plots simply and clearly. The ultra-small magnitude appears in $\left(\mathbf{Z}_{o}-\mathbf{Z}_{g}\right)$, which will result in a large magnitude in $\frac{1}{\operatorname{det}\left(\mathbf{Z}_{o}-\mathbf{Z}_{g}\right)}$, should be avoided for a stable operation.

With a constant grid impedance $\mathbf{Z}_{g}$, the stability influence of various $\mathbf{Y}_{o}$ is analysed based on (9) via $\frac{1}{\operatorname{det}\left(\mathbf{Y}_{g}-\mathbf{Y}_{o}\right)}$. Each element of $\left(\mathbf{Y}_{g}-\mathbf{Y}_{o}\right)$ is drawn as the bode plot for the stability analysis.

The inverter impedance $\mathbf{Z}_{o}$ based on the bode plot are widely used for the stability analysis including the vector control [5] or power synchronization control [26]. Therefore, in this paper, the theory based on (8) are applied. The bode plot of $\left(\mathbf{Z}_{o}-\mathbf{Z}_{g}\right)$ will be drawn for the stability analysis.

It should be noticed that the accurate stability analysis still requires the determinant of the impedance ratio matrix. Bode plots of $\left(\mathbf{Z}_{o}-\mathbf{Z}_{g}\right)$ are used to show the stability 
interaction between the inverter and the grid, and the stability improvement (avoid the ultra-small magnitude from $\left(\mathbf{Z}_{o}-\mathbf{Z}_{g}\right)$ ) can be find out via the bode plot.

\section{Virtual impedance control}

$\mathbf{Z}_{o}$ can be modified by adding additional impedance in order to avoid the ultra-small magnitude of $\left(\mathbf{Z}_{o}-\mathbf{Z}_{g}\right)$. The stability of the inverter system will be improved. The control parameter can be tuned to apply the required impedance. However, the inverter control is too complicated to find the proper parameters. The virtual impedance is the simple way to provide the required impedance for the $\mathbf{Z}_{o}$. Therefore, the virtual impedance control will be applied in this paper and what kind of virtual impedance for the vector control or power synchronization control is carried out based on $\left(\mathbf{Z}_{o}-\mathbf{Z}_{g}\right)$.

\section{THE DQ IMPEDANCE OF THE GRID-CONNECTED INVERTER}

The detailed structures of the power synchronization control and the vector control for the grid-connected inverter are shown in Fig. 3 and Fig. 4. The active power and the magnitude of the point of common coupling voltage $v_{f}$ are regulated via both control. The virtual impedance control are added in order to enhance the system stability.

The $\mathrm{dq}$ admittance (and impedance) of the grid-connected inverter with the vector control is well derived and validated in [5]. Therefore only the impedance derivation for the power synchronization control is shown in this section.

\section{A. Linearization of the power synchronization}

For the dq impedance derivation, the three-phase abc system is presented as the dq form. The power is therefore calculated as below:

$$
P=\frac{3}{2}\left(V_{f d} I_{g d}+V_{f q} I_{g q}\right)
$$

If small disturbances are applied based on small-signal method, (10) is rewritten as:

$P+\widetilde{P}=\frac{3}{2}\left[\left(V_{f d}+\widetilde{v}_{f d}\right)\left(I_{g d}+\widetilde{i}_{g d}\right)+\left(V_{f q}+\widetilde{v}_{f q}\right)\left(I_{g q}+\widetilde{i}_{g q}\right)\right]$

The linearized power is yielded by rearranging (11):

$$
\widetilde{P} \approx 1.5\left(I_{g d} \widetilde{v}_{f d}+V_{f d} \widetilde{i}_{g d}+I_{g q} \widetilde{v}_{f q}+V_{f q} \widetilde{i}_{g q}\right)
$$

The power synchronization is shown based on the Fig. 3:

$$
\theta=\int \omega_{0}+d_{p}\left(P^{*}-P\right) d t-\frac{\pi}{2}
$$

Its equivalent small-signal function is:

$$
\widetilde{\theta}=\frac{d_{p}\left(\widetilde{P}^{*}-\widetilde{P}\right)}{s}
$$

The linearization of the power synchronization is achieved via substituting $\widetilde{P}$ in (14) with (11):

$$
\widetilde{\theta}=\frac{d_{p} \widetilde{P}^{*}}{s}-\frac{1.5 d_{p}}{s}\left(I_{g d} \widetilde{v}_{f d}+V_{f d} \widetilde{i}_{g d}+I_{g q} \widetilde{v}_{f q}+V_{f q} \widetilde{i}_{g q}\right)
$$

\section{B. Linearization of abc-dq transformation}

For the dq impedance derivation, the three-phase abc system is presented as the dq form, such as $\mathbf{v}_{c} \mathbf{v}_{f} \mathbf{i}_{c} \mathbf{i}_{g}$. The dq control is based on the synchronized dq frame, their parameter are therefore noted as $\mathbf{v}_{o}^{s} \mathbf{v}_{f}^{s} \mathbf{i}_{c}^{s} \mathbf{i}_{g}^{s}$. The dq-formed abc parameters are equal to their dq-synchronized parameters after the abc$\mathrm{dq}$ transformation at steady state, but are different when a synchronized phase error $\widetilde{\theta}$ appears at the transformation. The linearization of the abc-dq transformation is shown blow:

$$
\mathbf{T}=\left[\begin{array}{cc}
\cos (0+\widetilde{\theta}) & \sin (0+\widetilde{\theta}) \\
-\sin (0+\widetilde{\theta}) & \cos (0+\widetilde{\theta})
\end{array}\right] \approx\left[\begin{array}{cc}
1 & \widetilde{\theta} \\
-\widetilde{\theta} & 1
\end{array}\right]
$$

Transformation from dq to abc yields:

$$
\mathbf{T}^{-1} \approx\left[\begin{array}{cc}
1 & -\widetilde{\theta} \\
\tilde{\theta} & 1
\end{array}\right]
$$

The abc-dq transformation via $\mathbf{T}$ between $\mathbf{i}_{c}$ and $\mathbf{i}_{c}^{s}$ based on the small-signal method is summarized below:

$$
\begin{array}{r}
{\left[\begin{array}{c}
I_{c d}^{s}+{\widetilde{i_{c}^{s}}}_{c d}^{s} \\
I_{c q}^{s}+\widetilde{i}_{c q}^{s}
\end{array}\right]=\left[\begin{array}{cc}
1 & \widetilde{\theta} \\
-\widetilde{\theta} & 1
\end{array}\right]\left[\begin{array}{l}
I_{c d}+\widetilde{i}_{c d} \\
I_{c q}+\widetilde{i}_{c q}
\end{array}\right]=} \\
\\
{\left[\begin{array}{c}
I_{c d}+\widetilde{i}_{c d}+I_{c q} \widetilde{\theta}+\widetilde{\theta} \widetilde{i}_{c q} \\
I_{c q}+\widetilde{i}_{c q}-I_{c d} \widetilde{\theta}-\widetilde{\theta} i_{c d}
\end{array}\right]}
\end{array}
$$

(18) is simplified below based on $\mathbf{I}_{c}^{s}=\mathbf{I}_{c}$ and $\widetilde{\theta} \tilde{\mathbf{i}}_{c} \approx 0$ :

$$
\left[\begin{array}{c}
\widetilde{i}_{c d}^{s} \\
\widetilde{i}_{c q}^{s}
\end{array}\right]=\left[\begin{array}{c}
\widetilde{i}_{c d}+I_{c q} \widetilde{\theta} \\
\widetilde{i}_{c q}-I_{c d} \widetilde{\theta}
\end{array}\right]
$$

Substituting $\theta$ in (19) with (15) yields:

$$
\widetilde{\mathbf{i}}_{c}^{s}=\widetilde{\mathbf{i}}_{c}+\mathbf{H}_{c f} \widetilde{\mathbf{v}}_{f}+\mathbf{H}_{c g} \widetilde{\mathbf{i}}_{g}+\mathbf{H}_{c P} \widetilde{\mathbf{P}}^{*}
$$

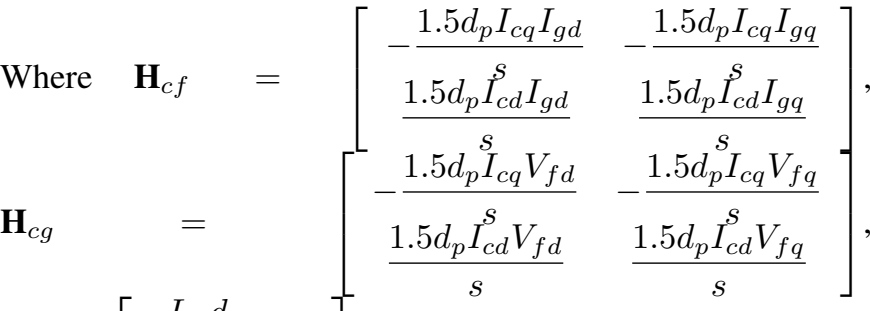

$$
\begin{aligned}
& \mathbf{H}_{c P}=\left[\begin{array}{cc}
\frac{I_{c q} d_{p}}{s} & 0 \\
-\frac{I_{c d} d_{p}}{s} & 0
\end{array}\right], \widetilde{\mathbf{P}}^{*}=\left[\begin{array}{c}
\widetilde{P}^{*} \\
0
\end{array}\right]
\end{aligned}
$$

The abc-dq transformations for $\mathbf{i}_{g} \& \mathbf{i}_{g}^{s}$ and $\mathbf{v}_{f} \& \mathbf{v}_{f}^{s}$ by following the same derivation yield:

$$
\widetilde{\mathbf{i}}_{g}^{s}=\mathbf{H}_{g f} \widetilde{\mathbf{v}}_{f}+\mathbf{H}_{g g} \widetilde{\mathbf{i}}_{g}+\mathbf{H}_{g P} \widetilde{\mathbf{P}}^{*}
$$

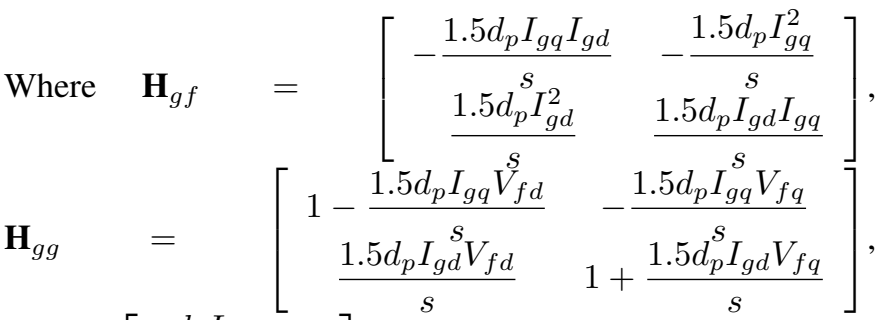

$$
\begin{aligned}
& \mathbf{H}_{g P}=\left[\begin{array}{cc}
\frac{d_{p} I_{g q}}{s} & 0 \\
-\frac{d_{p} I_{g d}}{s} & 0
\end{array}\right]
\end{aligned}
$$




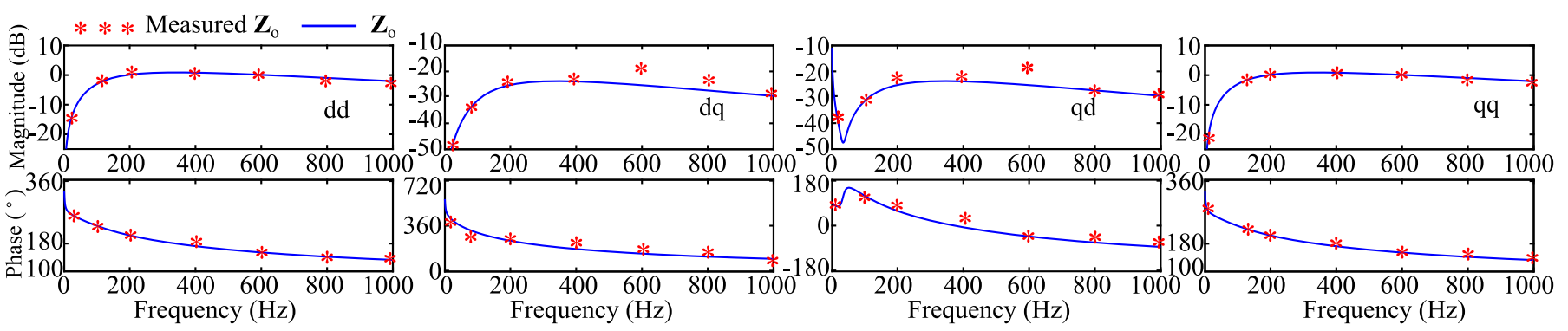

Fig. 5: Impedance measurement of the power synchronization control

$$
\widetilde{\mathbf{v}}_{f}^{s}=\mathbf{G}_{f f} \widetilde{\mathbf{v}}_{f}+\mathbf{G}_{f g} \widetilde{\mathbf{i}}_{g}+\mathbf{G}_{f P} \widetilde{\mathbf{P}}^{*}
$$

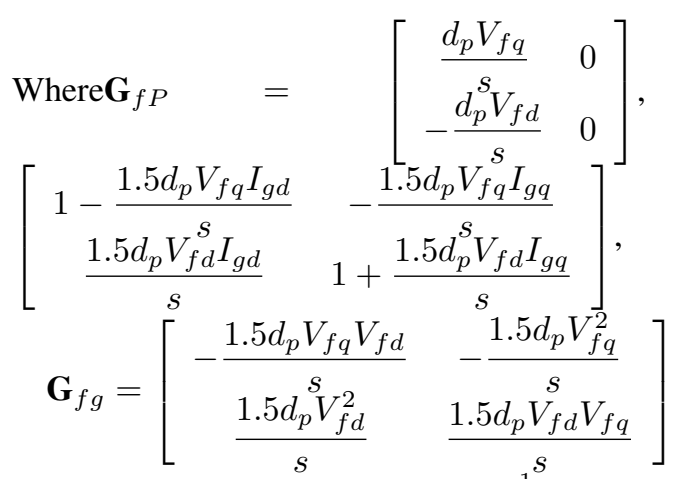

The dq-abc transformation via $\mathbf{T}^{-1}$ between $\mathbf{v}_{c}^{s}$ and $\mathbf{v}_{c}$ based on the similar derivation yields:

$$
\widetilde{\mathbf{v}}_{c}=\widetilde{\mathbf{v}}_{c}^{s}+\mathbf{G}_{c f} \widetilde{\mathbf{v}}_{f}+\mathbf{G}_{c g} \widetilde{\mathbf{i}}_{g}+\mathbf{G}_{c P} \widetilde{\mathbf{P}}^{*}
$$

$$
\begin{aligned}
& \text { Where } \mathbf{G}_{c f}=\left[\begin{array}{cc}
\frac{1.5 d_{p} V_{c q} I_{g d}}{1.5 d_{p} V_{c d} I_{g d}} & \frac{1.5 d_{p} V_{c q} I_{g q}}{s} \\
-\frac{1.5 d_{p} V_{c d} I_{g q}}{s}
\end{array}\right], \\
& \mathbf{G}_{c g} \\
& \mathbf{G}_{c P}=\left[\begin{array}{cc}
\frac{1.5 d_{p} V_{c q} V_{f d}}{s} & \frac{1.5 d_{p} V_{c q} V_{f q}}{s} \\
-\frac{d_{p} V_{c q}}{s} & 0 \\
\frac{d_{p} V_{c d}}{s} & 0
\end{array}\right],
\end{aligned}
$$

\section{Admittance and impedance of the grid-connected inverter}

The admittance of the inverter is built up from the control and LC filter of the inverter. The function of the inverter based on its admittance is shown in (1). The admittance is derived in this section and the impedance is the inverse admittance.

The dq control as shown in Fig. 3 is summarized below:

$\widetilde{\mathbf{v}}_{c}^{s}=\mathbf{t} \mathbf{f}_{i}\left[\mathbf{t}_{v}\left(\widetilde{\mathbf{v}}_{f}^{*}-\widetilde{\mathbf{v}}_{f}^{s}\right)+\widetilde{\mathbf{i}}_{g}^{s}+\mathbf{G}_{d e v} \widetilde{\mathbf{v}}_{f}^{s}-\widetilde{\mathbf{i}}_{c}^{s}\right]+\widetilde{\mathbf{v}}_{f}^{s}+\mathbf{G}_{d e i} \widetilde{\mathbf{i}}_{c}^{s}+\mathbf{Z}_{v} \widetilde{\mathbf{i}}_{c}^{s}$

$$
\begin{aligned}
& \text { Where } \quad \mathbf{t f}_{i}=\left[\begin{array}{cc}
k_{p}^{i}+\frac{k_{i}^{i}}{s} & 0 \\
0 & k_{p}^{i}+\frac{k_{i}^{i}}{s}
\end{array}\right], \quad \mathbf{t}_{v}= \\
& {\left[\begin{array}{cc}
k_{p}^{v}+\frac{k_{i}^{v}}{s} & 0 \\
0 & k_{p}^{v}+\frac{k_{i}^{v}}{s}
\end{array}\right], \mathbf{G}_{d e i}=\left[\begin{array}{cc}
0 & -\omega_{0} L_{f} \\
\omega_{0} L_{f} & 0
\end{array}\right],}
\end{aligned}
$$

$$
\begin{aligned}
& \mathbf{G}_{d e i}=\left[\begin{array}{cc}
0 & -\omega_{0} C_{f} \\
\omega_{0} C_{f} & 0
\end{array}\right], \mathbf{Z}_{v}=\left[\begin{array}{cc}
Z_{v} & 0 \\
0 & Z_{v}
\end{array}\right], \\
& \widetilde{\mathbf{v}}_{f}^{*}=\left[\begin{array}{c}
\widetilde{v}_{f d}^{*} \\
\widetilde{v}_{m a g}^{*}
\end{array}\right]
\end{aligned}
$$

Substituting $\widetilde{\mathbf{v}}_{c}^{s} \widetilde{\mathbf{v}}_{f}^{s} \widetilde{\mathbf{i}}_{c}^{s} \widetilde{\mathbf{i}}_{g}^{s}$ in (24) with (20) (21) (22) (23) and taking the time $T_{\text {del }}$ including control delay and the dead time of PWM into account yields:

$$
\widetilde{\mathbf{v}}_{c}=\mathbf{G}_{d e l} \mathbf{t} \mathbf{f}_{i} \mathbf{t} \mathbf{f}_{v} \widetilde{\mathbf{v}}_{f}^{*}+\mathbf{G}_{v} \widetilde{\mathbf{v}}_{f}+\mathbf{G}_{i} \widetilde{\mathbf{i}}_{g}+\mathbf{G}_{d e l} \mathbf{G}_{p} \widetilde{\mathbf{P}}^{*}
$$

Where $\mathbf{G}_{v}=\mathbf{G}_{d e l}\left[\left(\mathbf{I}-\mathbf{t f}_{i} \mathbf{t f}_{v}+\mathbf{t f}_{i} \mathbf{G}_{d e v}\right) \mathbf{G}_{f f}+\mathbf{t f}_{i} \mathbf{H}_{g f}+\left(\mathbf{G}_{d e i}-\right.\right.$ $\left.\left.\mathbf{t f}_{i}+\mathbf{Z}_{v}\right) \mathbf{H}_{c f}+\mathbf{G}_{c f}+\left(\mathbf{G}_{d e i}-\mathbf{t f}_{i}+\mathbf{Z}_{v}\right) \mathbf{Y}_{c}\right], \mathbf{G}_{i}=\mathbf{G}_{d e l}[(\mathbf{I}-$ $\left.\mathbf{t f} \mathbf{t f}_{v}+\mathbf{t f}_{i} \mathbf{G}_{d e v}\right) \mathbf{G}_{f g}+\mathbf{t f} \mathbf{f}_{i g}+\left(\mathbf{G}_{d e i}-\mathbf{t f} \mathbf{f}_{i}+\mathbf{Z} v\right) \mathbf{H}_{c g}+\mathbf{G}_{c g}+$ $\left.\left(\mathbf{G}_{d e i}-\mathbf{t f}_{i}+\mathbf{Z}_{v}\right)\right], \mathbf{G}_{d e l}=\left[\begin{array}{cc}\frac{1-0.5 T_{d e l} s}{1+0.5 T_{\text {del }} s} & 0 \\ 0 & \frac{1-0.5 T_{\text {del }} s}{1+0.5 T_{\text {del }} s}\end{array}\right]$

The voltage and current relation on the LC filter can be found below:

$$
\widetilde{\mathbf{v}}_{c}=\widetilde{\mathbf{v}}_{f}+\mathbf{Z}_{f} \tilde{\mathbf{i}}_{c}
$$

Where $\mathbf{Z}_{f}(s)=\left[\begin{array}{cc}L_{f} s+R_{f} & -\omega_{0} L_{f} \\ \omega_{0} L_{f} & L_{f} s+R_{f}\end{array}\right]$

$$
\widetilde{\mathbf{i}}_{c}=\mathbf{Y}_{c} \widetilde{\mathbf{v}}_{f}+\widetilde{\mathbf{i}}_{g}
$$

Where $\mathbf{Y}_{c}=\left[\begin{array}{cc}C_{f} s & -\omega_{0} C_{f} \\ \omega_{0} C_{f} & C_{f} s\end{array}\right]$

Substituting $\widetilde{\mathbf{i}}_{c}$ in (26) with (27) yields:

$$
\widetilde{\mathbf{v}}_{c}=\widetilde{\mathbf{v}}_{f}+\mathbf{Z}_{f} \mathbf{Y}_{c} \widetilde{\mathbf{v}}_{f}+\mathbf{Z}_{f} \widetilde{\mathbf{i}}_{g}
$$

Substituting $\widetilde{\mathbf{v}}_{c}$ in (25) with (28) yields:

$$
\widetilde{\mathbf{v}}_{f}+\mathbf{Z}_{f} \mathbf{Y}_{c} \widetilde{\mathbf{v}}_{f}+\mathbf{Z}_{f} \widetilde{\mathbf{i}}_{g}=\mathbf{G}_{d e l} \mathbf{t} \mathbf{f}_{i} \mathbf{t} \mathbf{f}_{v} \widetilde{\mathbf{v}}_{f}^{*}+\mathbf{G}_{v} \widetilde{\mathbf{v}}_{f}+\mathbf{G}_{i} \widetilde{\mathbf{i}}_{g}+\mathbf{G}_{d e l} \mathbf{G}_{p} \widetilde{\mathbf{P}}^{*}
$$

Rearranging (29) according to the structure of (1) yields:

$$
\begin{aligned}
\tilde{\mathbf{i}}_{g}=\underbrace{\left(\mathbf{Z}_{f}-\mathbf{G}_{i}\right)^{-1}\left(\mathbf{G}_{v}-\mathbf{Z}_{f} \mathbf{Y}_{c}-\mathbf{I}\right)}_{\mathbf{Y}_{o}} \widetilde{\mathbf{v}}_{f}+ & \underbrace{\left(\mathbf{Z}_{f}-\mathbf{G}_{i}\right)^{-1}\left(\mathbf{G}_{d e l} \mathbf{t} \mathbf{f}_{i} \mathbf{t} \mathbf{f}_{v} \widetilde{\mathbf{v}}_{f}^{*}+\mathbf{G}_{d e l} \mathbf{G}_{p} \widetilde{\mathbf{P}}^{*}\right)}_{\mathbf{G}_{r e f} \widetilde{\mathbf{r e f}}}
\end{aligned}
$$

The admittance $\mathbf{Y}_{o}$ of the inverter is therefore derived based on (30), and the impedance $\mathbf{Z}_{o}$ is derived as $\left(\mathbf{Y}_{o}\right)^{-1}$. 

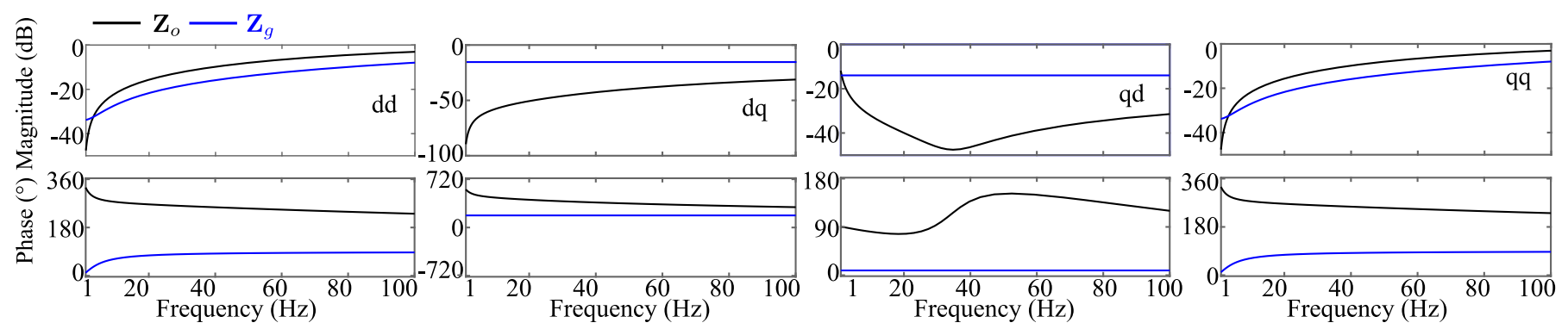

Fig. 6: Impedance analysis via the bode plots

\section{Impedance validation of the power synchronization control}

The derived impedance of the power synchronization control is validated via the measurement method [31]. The parameters of the inverter are shown in Table I. Two sets of 0.01 p.u. ac current are injected to the inverter because of 4 unknowns impedance elements $\left(Z_{o_{-} d d}, Z_{o_{-} d q}, Z_{o_{-} q d}, Z_{o_{-} q q}\right)$. The injection point is shown in Fig. 4. The measured dq impedance matrix is calculated based on the measurements $\widetilde{\mathbf{v}}_{f} \widetilde{\mathbf{i}}_{g}^{-1}$. The measured and derived impedance matrixes are drawn in Fig. 5. It shows good accuracy of the derived impedance matrix.

TABLE I: Parameters of the grid-connected inverter

\begin{tabular}{|c|c|c|}
\hline Symbol & Parameter & Value \\
\hline \multicolumn{3}{|c|}{ Grid-connected inverter } \\
\hline$S$ & Power rating & 1000 MVA \\
\hline$V_{g}$ & rms 1-1 AC grid voltage & $320 \mathrm{kV}$ \\
\hline$L_{f}$ & LC filter inductor & $48.9 \mathrm{mH}$ \\
\hline$R_{f}$ & LC filter resistor & $0.512 \Omega$ \\
\hline$C_{f}$ & LC filter capacitor & $2.05 \mu \mathrm{F}$ \\
\hline$Z_{g}\left(R_{g}+j X_{L_{g}}\right)$ & grid impedance & $0.02+0.2 j$ p.u. \\
\hline$v_{f d}^{*}$ & d-axis voltage reference & 1 p.u. \\
\hline$v_{f q}^{*}$ & $\mathrm{q}$-axis voltage reference & 0 p.u. \\
\hline$P^{*}$ & active power reference & 1 p.u. \\
\hline$T_{d e l}$ & control delay and dead time of PWM & $5 \mu \mathrm{s}$ \\
\hline$\omega^{*}$ & base frequency & $2 \pi \times 50$ \\
\hline \multicolumn{3}{|c|}{ Vector control } \\
\hline$\omega_{c}^{i}$ & cut-off frequency of closed-loop current control & $800 \mathrm{rad} / \mathrm{s}$ \\
\hline$k_{p}^{i} \& k_{i}^{i}$ & PI for current control & $0.382 \& 4$ \\
\hline$k_{p}^{P} \& k_{i}^{P}$ & PI for power control & $0.1 k_{p}^{i} \& 0.1 k_{i}^{i}$ \\
\hline$k_{p}^{v} \& k_{i}^{v}$ & PI for voltage control & $0.1 k_{p}^{i} \& 0.1 k_{i}^{i}$ \\
\hline$\omega_{c}^{P L L}$ & phase-locked loop cut-off frequency & $210 \mathrm{rad} / \mathrm{s}$ \\
\hline$k_{p}^{P L L} \& k_{i}^{P L L}$ & PI for PLL & $420 \& 44100$ \\
\hline \multicolumn{3}{|c|}{ Power synchronization control } \\
\hline$\omega_{c}^{i}$ & cut-off frequency of close-loop current control & $4000 \mathrm{rad} / \mathrm{s}$ \\
\hline$k_{p}^{i} \& k_{i}^{i}$ & PI for current control & $1.91 \& 20$ \\
\hline$k_{p}^{v} \& k_{i}^{v}$ & PI for voltage control & $0.1 k_{p}^{i} \& 0.1 k_{i}^{i}$ \\
\hline$d_{p}$ & power synchronization gain & $0.005 * \omega^{*}$ \\
\hline
\end{tabular}

\section{STABILITY ANALYSIS AND COMPARISON}

The stability of the vector control and the power synchronization control are analysed and compared in this section including:

- influence of the various grid impedance

- influence of the inner current control loop

- the stability enhancement of the virtual impedance

The grid-connected inverter systems shown Figs. 3 and 4 are simulated in Matlab/Simulink to validate the $\mathrm{dq}$ impedance stability analysis. The used parameters are given into Table I.

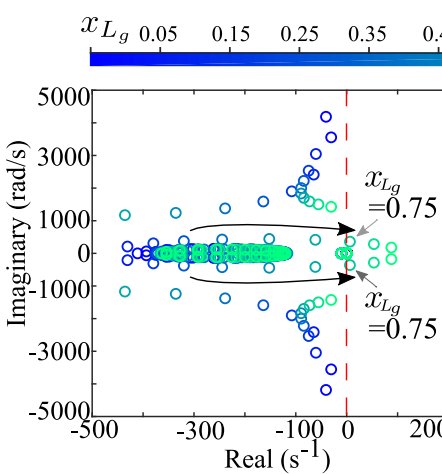

(a) Vector control

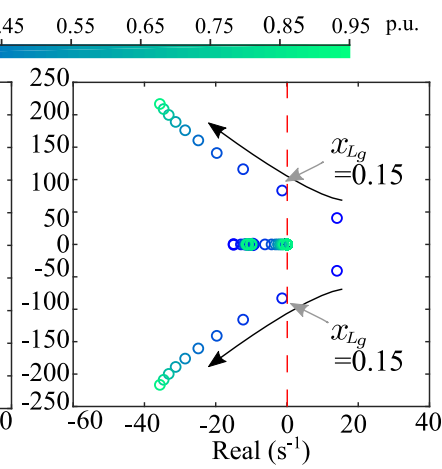

(b) Power synchronization control
Fig. 7: Determinant of the impedance ratio matrix with the grid impedance ranging from 0.05 to 0.95 p.u. $\left(X_{L g}\right)$

\section{A. Stability with the various grid impedance}

For a transmission network, the grid impedance is mainly inductive. The stability influence of the grid inductance $X_{L_{g}}$ ranging from 0.05 to 0.95 p.u. on the grid-connected inverter is studied. The grid resistance $R_{g}$ maintains $0.1 X_{L_{g}}$. The determinant of the impedance ratio matrix of the grid-connected inverters with the vector control and the power synchronization control are drawn in Fig. 7. The pole locus close to $x=0$ are shown. It is found that:

1) for an inverter with the vector control, increasing grid impedance makes the poles moving towards to the right half plane. The stability is therefore reduced. When $X_{L_{g}}>0.75$ p.u., the system becomes unstable as shown in Fig. 7 (a).

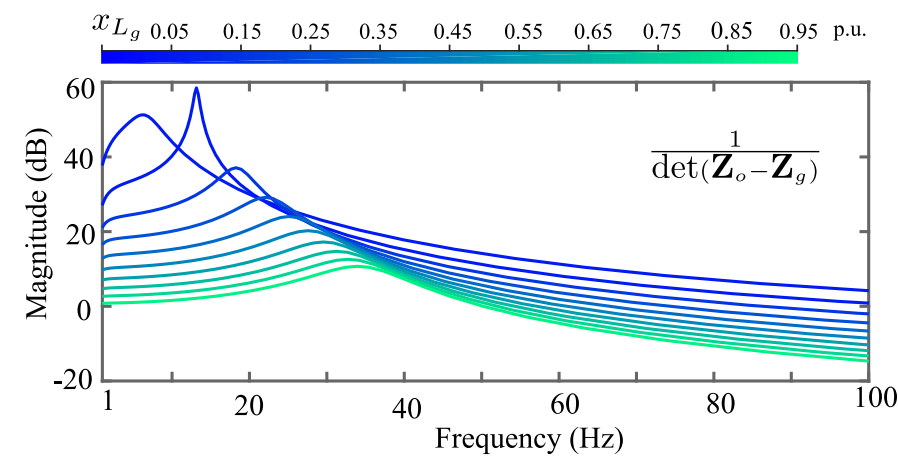

Fig. 8: Bode plot of $\frac{1}{\operatorname{det}\left(\mathbf{Z}_{o}-\mathbf{Z}_{g}\right)}$ with the grid impedance ranging from 0.05 to 0.95 p.u. 

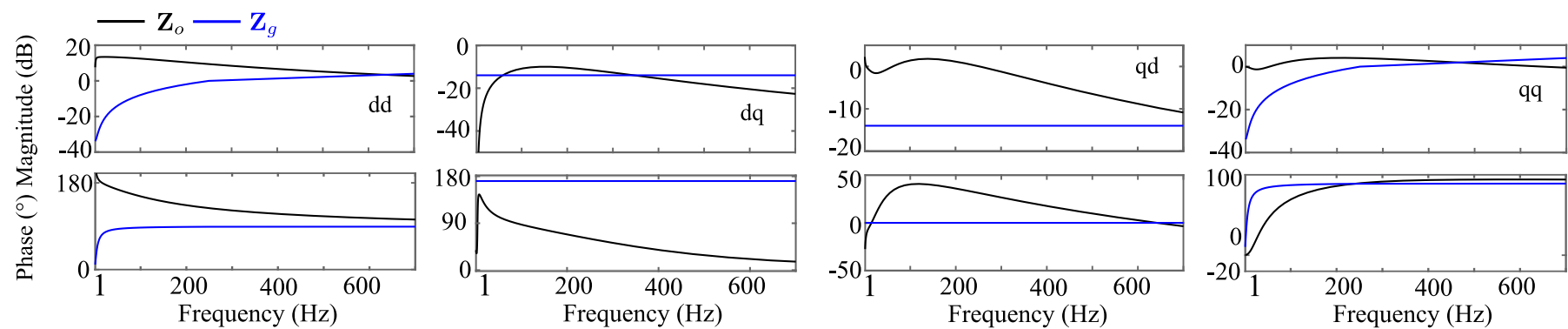

Fig. 9: Impedance of an inverter with the vector control

2) for an inverter with the power synchronization control, the inverter is more stable with the large grid impedance (weak grid), as shown in Fig. 7 (b).

3) for an inverter with the power synchronization control, decreasing the grid impedance makes the poles moving towards to the right half plane.The stability is therefore reduced. when $X_{L_{g}}<0.15$ p.u., the system becomes unstable as shown in Fig. 7 (b).

The findings 1) and 2) have been well analysed in [5] [23], which will not be explained in this paper. For explanation of 3), the impedance analysis based on (8) is applied for an inverter with the power synchronization control, as shown in Fig. 6. The dq and qd elements of $\mathbf{Z}_{o}$ are much smaller than the dd and qq element of grid impedance $\mathbf{Z}_{g}$. The dd and qq elements of $\mathbf{Z}_{o}$ are inductive and their phases are negative. Therefore, the magnitude of $\mathbf{Z}_{o}-\mathbf{Z}_{g}$ is the sum of both $\mathbf{Z}_{o}$ and $\mathbf{Z}_{g}$ magnitude. If the grid impedance is small, the magnitude of $\mathbf{Z}_{o}-\mathbf{Z}_{g}$ is small at low frequency range due to their inductive characteristic, which results in a large magnitude for $\frac{1}{\operatorname{det}\left(\mathbf{Z}_{o}-\mathbf{Z}_{g}\right)}$. As shown in Fig. 8, the peak magnitude is increased with decreasing the value of the grid impedance. In a summary, the inverter with the power-synchronization control may suffer instabilities with a strong grid.

\section{B. Stability with various cut-off frequency of the inner current control loop}

The closed-loop cut-off frequency $\left(\omega_{c}^{i}\right)$ is normally used to design the PI for the current loop. Both control contain the inner current loop to avoid the overload. Therefore, the stability influences of $\omega_{c}^{i}$ ranging from 800 to $8000 \mathrm{rad} / \mathrm{s}$ on both control are analysed. The outer loop PI is ten times slower. The determinant of the impedance ratio matrix based on the grid-connected inverters with the vector control and the power synchronization control are drawn in Fig. 10. The pole locus close to $x=0$ are shown. It is found that:

1) for an inverter with the vector control, increasing $\omega_{c}^{i}$ makes the poles towards to the right half plane. The instability happens with a high $\omega_{c}^{i}$ such as $\omega_{c}^{i}>5714$ $\mathrm{rad} / \mathrm{s}$, as shown in Fig. 10 (a).

2) for an inverter with the power synchronization control, increasing $\omega_{c}^{i}$ makes the poles away from the right half plane. The instability happens with a low $\omega_{c}^{i}$ such as $\omega_{c}^{i}<2667 \mathrm{rad} / \mathrm{s}$ as shown in Fig. 10 (b).

It is shown from Figs. 10 (a) and 10 (b) that the design of the inner current loop for the vector control is different from the

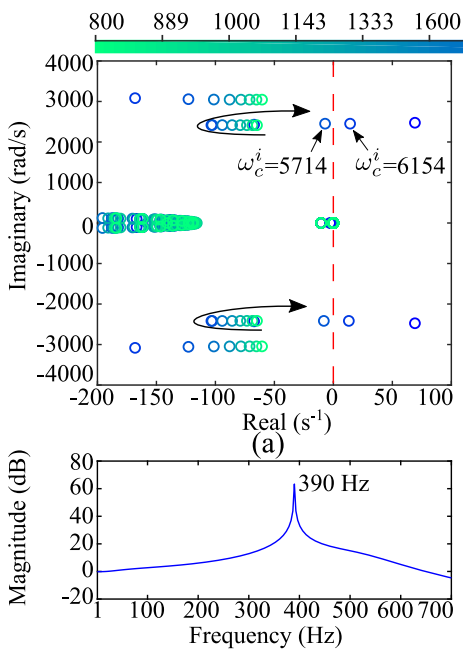

(c)
Vector control
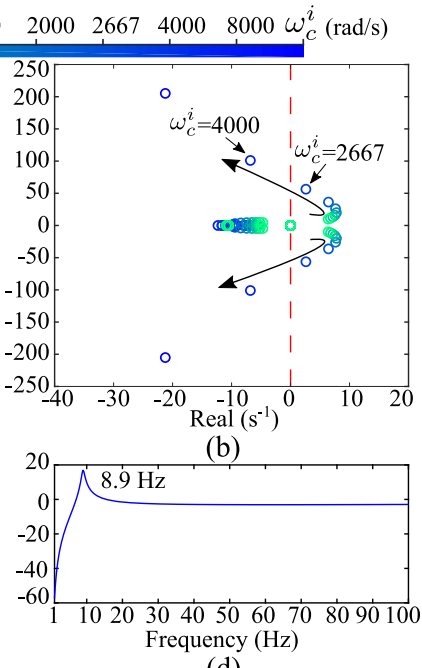

(d)

Power synchronization control

Fig. 10: Determinant of the impedance ratio matrix with various close-loop cut-off frequency $\left(\omega_{c}^{i}\right)$ of the inner current loop

inner current loop of power synchronization control. Reducing $\omega_{c}^{i}$ helps to stabilize the inverter with the vector control. Conversely, increasing $\omega_{c}^{i}$ helps to stabilize the inverter with the power synchronization control. The determinants of the impedance ratio matrix for both control are also drawn as bode plots to find out their resonant frequency when $\omega_{c}^{i}=6154$ and $\omega_{c}^{i}=2667$ respectively, as shown in Figs. 10 (c) and 10 (d). It is found that ultra-high magnitudes appear at $390 \mathrm{~Hz}$ and $8.9 \mathrm{~Hz}$ respectively under the vector control and the power synchronization control.

The stability analysis and resonant frequency analysis based on pole maps and bode plots are validated via the simulation. Two poles that close to $x=0$ are selected and pointed out in Fig. 10 (a) and 10 (b). Values of $\omega_{c}^{i}$ of the two poles are also shown. The simulation results for the selected poles are shown in Fig. 11. For the inverter with the vector control, the system is stable at $\omega_{c}^{i}=5714 \mathrm{rad} / \mathrm{s}$ and unstable at $\omega_{c}^{i}=$ $6154 \mathrm{rad} / \mathrm{s}$ as shown in Fig. 11 (a). Similar stability result is found at the inverter with the power synchronization control, as shown in Fig. 11 (b). The simulation results matches the stability analysis based on the pole map. The Fourier analysis results are shown in Figs. 11 (c) and 11 (d). The main resonant frequency after $1 \mathrm{~s}$ of $i_{g d}$ for both control are $388 \mathrm{~Hz}$ and $9 \mathrm{~Hz}$ 
respectively, which also matches to the analysis results from bode plots.

\section{Stability with the virtual impedance}

The virtual impedance are added in the control as shown in Figs. 3 and 4 for modifying the impedance $\mathbf{Z}_{o}$ of the inverter based on the bode plots of $\mathbf{Z}_{o}$ and $\mathbf{Z}_{g}$. The ultrasmall magnitude appearing in $\operatorname{det}\left(\mathbf{Z}_{o}-\mathbf{Z}_{g}\right)$ should be avoided in order to enhance the stability. The bode plots of $\mathbf{Z}_{o}$ for both control are drawn in Figs. 6 and 9 based on the inductive impedance $\mathbf{Z}_{g}$. It is found that:

1) for the vector control, as shown in Fig. $9, \mathbf{Z}_{o}$ behaves like a capacitive impedance. There are crossing points of $\mathbf{Z}_{o}$ and $\mathbf{Z}_{g}$ in the magnitude of both dd and qq elements. If their phases are close at the crossing points which results in a large magnitude of $\frac{1}{\operatorname{det}\left(\mathbf{Z}_{o}-\mathbf{Z}_{q}\right)}$, the risk of instability increases. Especially for the qq element, a larger grid impedance will make the magnitude crossing point more close to the phase crossing point. It can be avoided by adding the virtual inductor.

2) for the power synchronization control, as shown in Fig. $6, \mathbf{Z}_{o}$ behaves like an inductive impedance. There are no crossing points at the mid frequency range. However, $\mathbf{Z}_{o}$ has a small magnitude at the low frequency, which results in a large magnitude in $\frac{1}{\operatorname{det}\left(\mathbf{Z}_{o}-\mathbf{Z}_{o}\right)}$. If the grid impedance is reduced, the risk of the instability increases. The virtual resistance can be inserted to change the magnitude of $\mathbf{Z}_{o}$ at low frequency range to avoid the risk of the instability.

The unstable cases of both control on $w_{c}^{i}=6154$ and $2667 \mathrm{rad} / \mathrm{s}$ respectively (as shown in Fig. 11 ) are used to validate the effectiveness of virtual impedance. The bode blots of

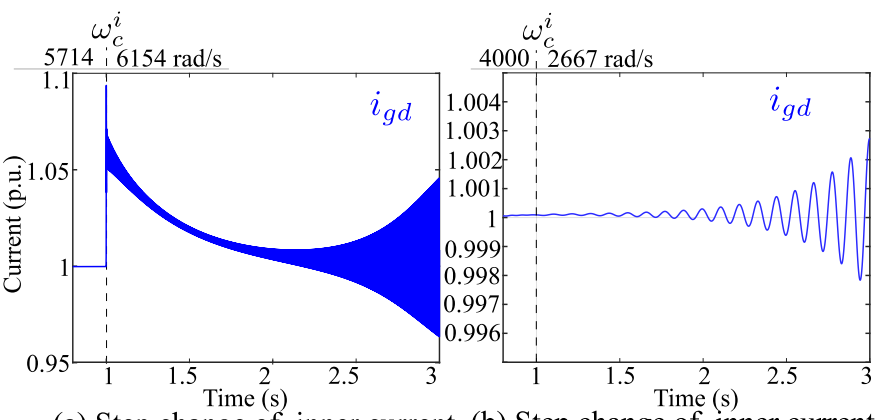

(a) Step change of inner current (b) Step change of inner current loop's cut-off frequency

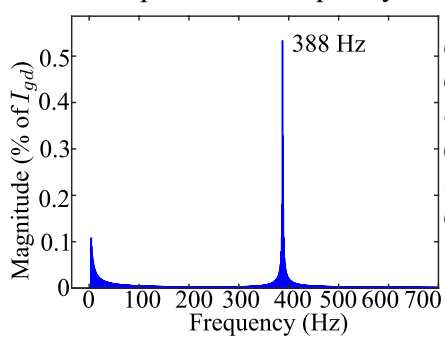

(c) Frequency analysis of $i_{g d}$ Vector control

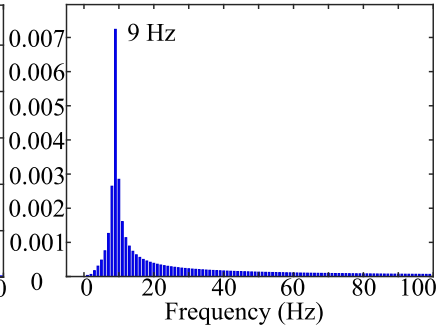

(d) Frequency analysis of $i_{g d}$

Power synchronization control
Fig. 11: Simulation validation of the inner current loop based on its cut-off frequency
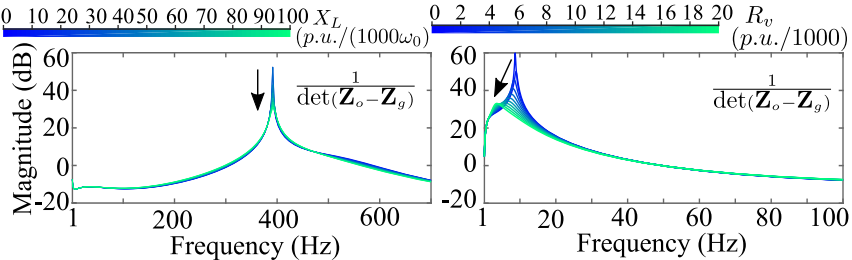

(a) bode plot impedance analysis (b) bode plot impedance analysis

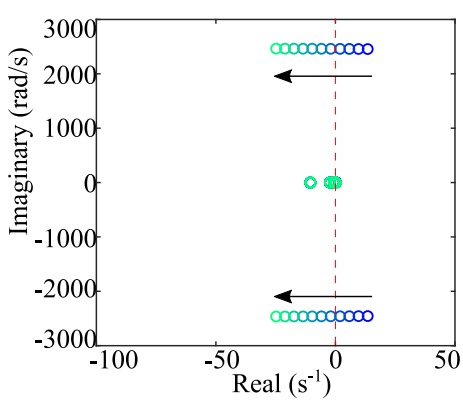

(c) pole map of the determinant

Vector control virtual inductor

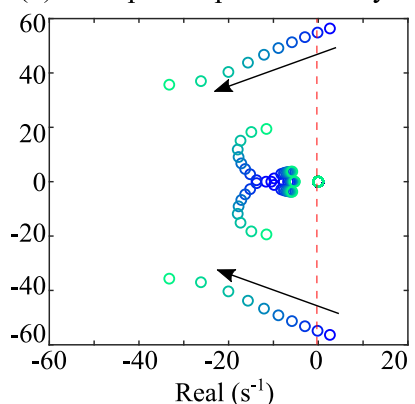

(d) pole map of the determinant

Power synchronization control virtual resistor

Fig. 12: Stability improvement using virtual impedance

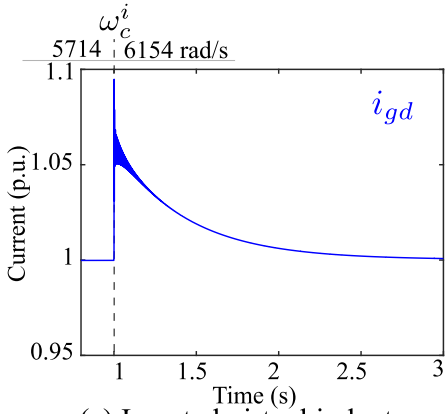

(a) Inserted virtual inductor $L_{v}=3.18 \times 10^{-4}$ p.u.

Vector control

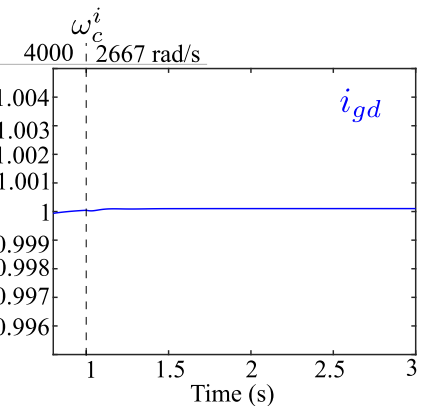

(b) Inserted virtual resistor $R_{v}=0.02$ p.u.

Power synchronization control
Fig. 13: Stability improvement validation for the virtual impedance

$\frac{1}{\operatorname{det}\left(\mathbf{Z}_{o}-\mathbf{Z}_{q}\right)}$ for both control are drawn in Figs. 12 (a) and 12 (b). It is found that both peak magnitude are reduced significantly with the increasing virtual inductance and resistance. The determinants of the impedance ratio matrix for both control are also drawn. The pole locus close to $x=0$ are shown in Figs. 12 (c) and 12 (d). Increasing virtual inductance and resistance make the poles moving to the left half plane for the vector control and the power synchronization control respectively, which validate the effectiveness of the virtual impedance for enhancing the stability of a grid-connected inverter.

The effectiveness of the virtual impedance for both control is also validated via the simulation. The maximum values of the virtual impedance from Figs. 12 (a) and 12 (b) are selected, where are $L_{v}=3.18 \times 10^{-4}$ p.u. and $R_{v}=0.02$ p.u.. When a step change of $w_{c}^{i}$ happens at $1 \mathrm{~s}$, the inverter is still stable with the inserted virtual impedance for both control, as shown in Fig. 13. On the contrary, the inverters with both control lose stability without the virtual impedances as shown in Figs. 11 (a) and 11 (b). 


\section{CONCLUSION}

For a grid-connected inverter requiring for the $\mathrm{AC}$ voltage magnitude and active power control, the stability comparison between the power synchronization control and the vector control is achieved based on the dq impedance stability analysis. Stability influence of three factors including the grid impedance, the inner current loop and the virtual impedance on both control are analysed and compared. It is concluded that:

1) The power synchronization control could suffer instabilities when a strong grid is connected. Because its impedance model behaves capacitively, which is small at low frequency range. On the contrary, the stability of the inverter with the vector control is weakened when the grid impedance increases.

2) Increasing the cut-off frequency of the inner current loop helps to stabilize the inverter with the power synchronization control, which is converse to the inverter with the vector control.

3) It is found that the impedances of the vector control and the power synchronization control are capacitive and inductive respectively. Therefore, the virtual resistance helps to stabilize the inverter with the power synchronization control. The virtual inductance helps to stabilize the inverter with the vector control. Value of the virtual impedance can be determined via the derived impedance models.

\section{REFERENCES}

[1] M. Liserre, R. Teodorescu, and F. Blaabjerg, "Stability of photovoltaic and wind turbine grid-connected inverters for a large set of grid impedance values," IEEE Transactions on Power Electronics, vol. 21, no. 1, pp. 263-272, Jan. 2006.

[2] L. Zhang, L. Harnefors, and H.-P. Nee, "Power-synchronization control of grid-connected voltage-source converters," IEEE Transactions on Power Systems, vol. 25, DOI 10.1109/TEC.2017.2766217, no. 2, pp. 809-820, May. 2010.

[3] P. Kundur, Power System Stability and control, 1st ed., ch. 12, pp. 699822. New York: McGraw-Hill, Inc., 1994.

[4] J. Sun, "Impedance-based stability criterion for grid-connected inverters," IEEE Transactions on Power Electronics, vol. 26, no. 11, pp. 30753078, Nov. 2011.

[5] B. Wen, dushan Boroyevich, R. Burgos, P. Mattavelli, and Z. Shen, "Analysis of d-q small-signal impedance of grid-tied inverters," IEEE Transactions on Power Electronics, vol. 31, no. 1, pp. 675-687, Jan. 2016.

[6] M. Cespedes and J. Sun, "Impedance modeling and analysis of gridconnected voltage-source converters," IEEE Transaction on Power Electronics, vol. 29, no. 3, pp. 1254-1261, Mar. 2014.

[7] L. Harnefors, "Modeling of Three-Phase Dynamic Systems Using Complex Transfer Functions and Transfer Matrices," IEEE Transactions on Industrial Electronics, vol. 54, DOI 10.1109/TIE.2007.894769, no. 4, pp. 2239-2248, 2007.

[8] X. Wang, L. Harefors, and F. Blaabjerg, "Unified impedance model of grid-connected voltage-source converters," IEEE Transactions on Power Electronics, vol. 33, no. 2, pp. 1775-1787, Feb. 2018.

[9] A. Rygg, M. Molinas, C. Zhang, and X. Cai, "A modified sequencedomain impedance definition and its equivalence to the dq-domain impedance definition for the stability analysis of ac power electronic systems," IEEE Journal of Emerging and Selected Topics in Power Electronics, vol. 4, no. 4, pp. 1383-1396, Octorber 2016.

[10] R. Burgos, D. Boroyevich, F. Wang, K. Karimi, and G. Francis, "On the ac stability of high power factor three-phase rectifiers," in 2010 IEEE Energy Conversion Congress and Exposition, pp. 2047-2054, Sep. 2010.
[11] Y. Xu, H. Nian, T. Wang, L. Chen, and T. Zheng, "Frequency coupling characteristic modeling and stability analysis of doubly fed induction generator," IEEE Transactions on Energy Conversion, vol. 33, DOI 10.1109/TEC.2018.2800043, no. 3, pp. 1475-1486, Sep. 2018.

[12] M. kazem Bakhshizadeh, X. Wang, F. Blaabjerg, J. Hjerrild, L. Kocewiak, C. L. Bak, and B. Hesslbak, "Couplings in phase domain impedance modeling of grid-connected converters," IEEE Transactions on Power Electronics, vol. 31, no. 10, pp. 6792-6797, Octorber 2016.

[13] B. Wen, D. Boroyevich, P. Mattavelli, Z. Shen, and R. Burgos, "Influence of phase-locked loop on input damittance of three-phase voltage-source converters," in 2013 Twenty-Eighth Annual IEEE Applied Power Electronics Converence and Exposition(APEC), pp. 897-904, Mar. 2013.

[14] B. Wen, D. Dong, D. Boroyevich, R. Burgos, P. Mattavelli, and Z. Shen, "Impedance-based analysis of grid-synchronization stability for threephase paralleled converters," IEEE Transactions on Power Electronics, vol. 31, no. 1, pp. 26-38, Jan. 2016.

[15] B. Wen, D. Boroyevich, R. Burgos, P. Mattavelli, and Z. Shen, "Smallsignal stability analysis of three-phase ac systems in the presence of constant power loads based on measured d-q frame impedances," IEEE Transactions on Power Electronics, vol. 30, no. 10, pp. 5952-5963, Oct. 2015.

[16] Z. Liu, J. Liu, X. Hou, Q. Dou, D. Xue, and T. Liu, "Output impedance modeling and stability prediction of three-phase paralleled inverters with master-slave sharing scheme based on terminal characteristics of individual inverters," IEEE Transactions on Power Electronics, vol. 31 no. 7, pp. 5306-5320, Jul. 2016.

[17] S. Hiti, V. Vlatkovic, D. Borojevic, and F. C. Lee, "A new control algorithm for three-phase pwm buck rectifier with input displacement factor compensation," in Proceedings of IEEE Power Electronics Specialist Conference - PESC '93, pp. 648-654, Jun. 1993.

[18] H. Mao, D. Boroyevich, and F. C. Y. Lee, "Novel reduced-order smallsignal model of a three-phase pwm rectifier and its application in control design and system analysis," IEEE Transactions on Power Electronics, vol. 13, no. 3, pp. 511-521, May. 1998.

[19] W. Cao, Y. Ma, L. Yang, F. Wang, and L. M. Tolbert, "D-q impedance based stability analysis and parameter design of three-phase inverterbased ac power systems," IEEE Transactions on Industrial Electronics, vol. 64, no. 7, pp. 6017-6028, Jul. 2017.

[20] H. Liu, X. Xie, and W. Liu, "An oscillatory stability criterion based on the unified $d q$-frame impedance network model for power systems with high-penetration renewables," IEEE Transactions on Power Systems, vol. 33, DOI 10.1109/TPWRS.2018.2794067, no. 3, pp. 3472-3485, May. 2018.

[21] C. Zhang, X. Cai, A. Rygg, and M. Molinas, "Sequence domain siso equivalent models of a grid-tied voltage source converter system for small-signal stability analysis," IEEE Transactions on Energy Conversion, vol. 33, DOI 10.1109/TEC.2017.2766217, no. 2, pp. 741-749, Jun. 2018.

[22] L. Harnefors, M. Bongiorno, and S. Lundberg, "Input-admittance calculations and shaping for controlled voltage-source converters," IEEE Transactions on Industrial Electronics, vol. 54, no. 6, pp. 3323-3334, Dec. 2007.

[23] L. Zhang, H.-P. Nee, and L. Harnefors, "Analysis of stability limitations of a vsc-hvdc link using power-synchronization control," IEEE Transactions on Power Systems, vol. 26, no. 3, pp. 1326-1337, Aug. 2011.

[24] L. harnefors, M. Hinkkanen, U. Riaz, F. M. Rahman, and L. Zhang, "Robust analytic design of power-synchronization control," IEEE Transactions on Industrial Electronics, vol. 66, no. 8, pp. 5810-5819, Aug. 2019.

[25] H. Wu and X. Wang, "Design-oriented transient stability analysis of grid-connected converters with power synchronization control," IEEE Transactions on Industrial Electronics, vol. 66, no. 8, pp. 6473-6482, Aug. 2019.

[26] K. M. Alawasa and Y. A.-R. I. Mohamed, "Impedance and damping characteristics of grid-connected vscs with power synchronization control strategy," IEEE Transactions on Power Systems, vol. 30, no. 2, pp. 952-961, Mar. 2015.

[27] Z. M. Javad Khazaei and L. Piyasinghe, "Impedance-model-based mimo analysis of power synchronization control," Electric Power Systems Research, vol. 154, pp. 341-351, Mar. 2018.

[28] E. Unamuno, A. Rygg, M. Amin, M. Molinas, and J. A. Barrena, "Impedance-based stability evaluation of virtual synchronous machine implementations in converter controllers," in 2018 International Power Electronics Conference (IPEC-Niigata 2018 -ECCE Asia), DOI 10.23919/IPEC.2018.8507905, pp. 759-766, May. 2018. 
[29] B. Wen, D. Boroyevich, R. Burgos, P. Mattavelli, and Z. Shen, "Inverse nyquist stability criterion for grid-tied inverters," IEEE Transactions on Power Electronics, vol. 32, no. 2, pp. 1548-1556, Feb. 2017.

[30] C. Li, T. Qoria, F. Colas, J. Liang, W. Ming, F. Gruson, and X. Guillaud, "Coupling influence on the dq impedance stability analysis for the threephase grid-connected inverter," energies, vol. 12, DOI 10.17775/CSEEJPES.2017.0015, no. 19, pp. 1-16, Sep. 2019.

[31] J. Huang, K. A. corzine, and M. Belkhayat, "Small-signal impedance measurement of power-electronics-based ac power systems using line-toline current injection," IEEE Transaction on Power Electronics, vol. 24, DOI 10.17775/CSEEJPES.2017.0015, no. 2, pp. 445-455, Feb. 2009.

[32] S.-K. Chung, "A phase tracking system for three phase utility interface inverters," IEEE Transactions on Power Electronics, vol. 15, no. 3, pp. 431-438, May. 2000.

[33] A. Yazdani and R. Iravani, Voltage-Sourced Converters in Power Systems, 1st ed., ch. 8, pp. 204-205. New Jersey: John Wiley \& Sons, Inc., 2010.

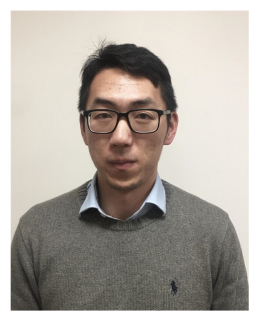

Chuanyue Li (M'17) received the B.Eng. degrees from both Cardiff University, UK and North China Electric Power University, China, in 2013 and the Ph.D. degree from Cardiff University, UK, in 2017. In 2018, he was a post-doc at the Laboratory of Electrical Engineering and Power Electronics (L2EP), Lille, France. Currently, He is a Research Associate at the School of Engineering, Cardiff University, Wales, UK. His research interests include HVDC control and protection, power electronics.

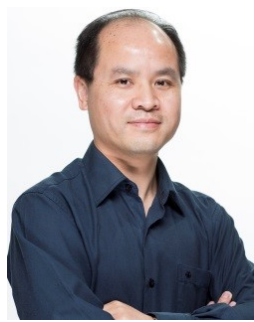

Jun Liang (M'02-SM'12) received the B.Sc. degree from Huazhong University of Science and Technology, Wuhan, China, in 1992 and the M.Sc. and $\mathrm{Ph} . \mathrm{D}$. degrees from the China Electric Power Research Institute (CEPRI), Beijing, in 1995 and 1998, respectively. From 1998 to 2001, he was a Senior Engineer with CEPRI. From 2001 to 2005, he was a Research Associate with Imperial College London, U.K.. From 2005 to 2007, he was with the University of Glamorgan as a Senior Lecturer. Currently, he is a Professor at the School of Engineering, Cardiff University, Cardiff, U.K.. He is a Fellow of the Institution of Engineering and Technology (IET). He is the Chair of IEEE UK and Ireland Power Electronics Chapter. He is an Editorial Board Member of CSEE JPES. He is the Coordinator and Scientist-in-Charge of two EC Marie- Curie Action ITN/ETN projects: MEDOW (€3.9M) and InnoDC $(€ 3.9 \mathrm{M})$. His research interests include HVDC, MVDC, FACTS, power system stability control, power electronics, and renewable power generation.

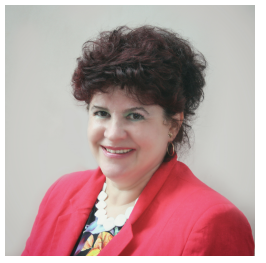

Liana M. Cipcigan (M'08) is a Professor at Cardiff University's School of Engineering leading Sustainable Transport cross-cutting theme. She is Director of the Electric Vehicle Centre of Excellence and leader of Transport Futures Research Network. She was at the forefront of the shift to electrified transport for over a decade being recognised nationally and internationally as an expert in EVs and Smart Grids leading the £1M EPSRC Network+ "Decarbonising Transport through Electrification (DTE), a Whole system approach". She has collaborated widely with industry, more recently during her secondment at National Grid under Royal Academy of Engineering Industrial Fellowship, working in the Energy Insights department responsible for the Future Energy Scenarios. She has held as PI and Co-I grants in the excess of $£ 6.5 \mathrm{M}$ from EPSRC, Royal Academy of Engineering, Innovate UK, UKERC, Welsh European Funding Office, EU FP7/H2020 and industry.

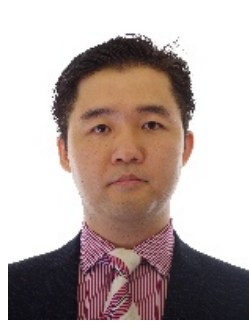

Wenlong Ming (M'16) received the B.Eng. and M.Eng. Degrees in Automation from Shandong University, Jinan, China, in 2007 and 2010, respectively. He received the Ph.D. degree in Automatic Control and Systems Engineering from the University of Sheffield, Sheffield, U.K., in 2015. He was the winner of the prestigious IET Control \& Automation Doctoral Dissertation Prize in 2017. He has been a Lecturer of Power Electronics at Cardiff University, U.K., since August 2016 and a Senior Research Fellow funded by Compound Semiconductor Applications (CSA) Catapult, U.K., for 5 years since April 2020

He was with the Center for Power Electronics Systems (CPES), Virginia Tech, Blacksburg, USA in 2012 as an academic visiting scholar. He has (co)authored more than 50 papers published in leading journals or refereed IEEE conferences. His research interests focus on Medium Voltage DC systems for electricity distribution networks and characterisation, modelling, applications of wide-bandgap compound semiconductors.

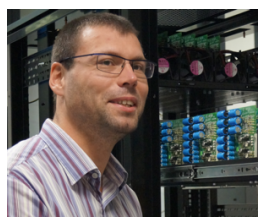

Frederic Colas was born in Lille, France, on October 17,1980 . He received a $\mathrm{PhD}$ in control system in 2007 from Ecole Centrale de Lille (France). Frédéric Colas is a member of the Laboratory of Electrical Engineering (L2EP) in Lille and is a Research Engineer at Arts et Métiers Paristech, 8 boulevard Louis XIV, 59046 Lille, France. His field of interest includes the integration of dispersed generation systems in electrical grids, advanced control techniques for power system and hardware-in-theloop simulation.

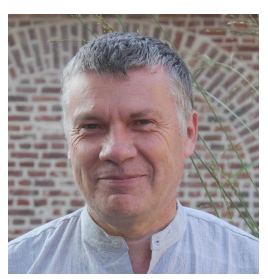

Xavier Guillaud received his $\mathrm{Ph} . \mathrm{D}$ from University of Lille in 1992 and joined the Laboratory of Electrical Engineering and Power Electronic (L2EP) in 1993. He has been professor in Ecole Centrale of Lille since 2002. First, he worked on modeling and control of power electronic systems. Then, he studied the integration of distributed generation and especially renewable energy. Nowadays, he is more focused on the integration of high voltage power electronic converters in the transmission system. $\mathrm{He}$ is leading the development of an experimental facility composed of actual power electronic converters interacting with virtual real-time simulated grids. He is involved on several projects about power electronic on the grid within European projects and a large number of projects with French electrical utilities. He is member of the Technical Program Committee of Power System Computation Conference (PSCC) and associated editor of Sustainable Energy, Grids and Networks (SEGAN). 